\title{
EVALUATION OF CORROSIVITY OF INDOOR MUSEUM ATMOSPHERES USING LEAD SPECIMENS
}

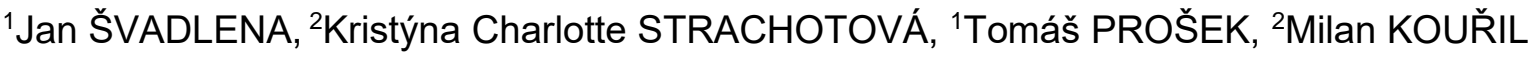 \\ ${ }^{1}$ Technopark Kralupy of the University of Chemistry and Technology Prague, Kralupy nad Vltavou, \\ Czech Republic, EU, jan.svadlena@vscht.cz \\ 2University of Chemistry and Technology Prague, Department of Metals and Corrosion Engineering, Prague, \\ Czech Republic, EU
}

https://doi.org/10.37904/metal.2020.3631

\begin{abstract}
The corrosivity of indoor atmospheres is usually evaluated according to the ISO 11844-1 standard, utilizing specimens of different metals. However, the sensitivity of this setup is not sufficient to the presence of specific organic pollutants, such as acetic and formic acid or formaldehyde. In this study, lead metal specimens were added as complementary specimens in the series of exposures including various museums and cultural sites. Temperature and relative humidity were monitored and adsorbent tubes were deployed for estimation of the content of the organic compound. For comparison and verification, lead specimens were exposed in laboratory conditions with controlled levels of acetic acid, which is supposed to be the main cause of the increase in lead corrosion rates. The results show that the use of lead specimens can provide valuable data about the corrosivity of the atmosphere due to its sensitivity to the presence of the carboxylic acids. This can be particularly important information for indoor storage conditions in museums and depositories. However, a proper method to evaluate the lead corrosion rates is necessary.
\end{abstract}

Keywords: Lead, atmospheric corrosion, indoor atmosphere

\section{INTRODUCTION}

Lead is a common metal material among the various objects of cultural heritage, including seals, coins, statues, stained glass, organ pipes or objects of everyday life. In common atmospheric conditions, lead is considered a stable metal with low corrosion rates due to the thin protective layer of corrosion products [1-4]. Based on the conditions, the composition of the corrosion products may include lead oxides, sulphide, chloride and especially lead carbonates in several mineral forms - cerussite, hydrocerussite or plumbonacrite. The level of protective properties of the layers of corrosion products depends mainly on relative humidity. In conditions with high humidity, voluminous corrosion products without protective properties are usually formed on the lead surface instead of a thin protective layer [1-6].

The presence of the organic pollutants in the atmosphere can significantly alter the lead corrosion behavior. Formic and acetic acid has the most pronounced effect on the lead corrosion rate [7-10]. Even at a concentration of $0.1 \mathrm{ppm}$, the presence of organic acid vapours is highly corrosive to the lead surface [9-12]. Unlike other lead compounds, lead acetates and formats are relatively soluble. Therefore, corrosion products formed in the atmosphere with acetic or formic acid vapours and high relative humidity do not provide any protective effect. Moreover, it is possible for the acid and formic acid to be partially released from the corrosion products and further participate in the corrosion process [1, 9-10].

Because of the described sensitivity, measurement of the lead corrosion rates can provide valuable information about the corrosivity of indoor atmospheres caused by the presence of volatile organic compounds. This is 
particularly important for conditions in museum repositories and archives where, based on the material of the indoor equipment, the concentration of acetic acid can be up to 20 times higher than outdoors [2]. Metal specimens used in the ISO 11844 standard may not provide sufficient sensitivity for this type of assessment [13].

The main goal of the study was to evaluate the possibility of use of lead specimens to determine the corrosivity of indoor atmospheres.

\section{EXPERIMENTAL PART}

\subsection{Exposure sites}

To evaluate the corrosivity of indoor museum atmospheres and the benefit of adding lead specimens to the standard procedure, six different sites were chosen for 3-months exposure:

- $\quad$ UCT Prague - Historic Library

- UCT Prague - Mineralogical collection (with old cabinets for the collection)

- $\quad$ National Archive - Hradčanská (archive room)

- $\quad$ National Library - open shelf in baroque hall in Klementinum

- Central Bohemian Museum in Roztoky u Prahy - depository VU (new depository of fine arts with controlled conditions)

- $\quad$ Central Bohemian Museum in Roztoky u Prahy - depository H

During the exposures, climatic parameters were monitored and the average concentration of acetic and formic acid in the atmosphere was estimated using passive samplers for long-term measurement and short-term detection tubes with a gas pump.

\subsection{Samples}

Series of silver, copper and lead metal specimens were prepared for each exposure site. Silver and copper specimens are part of the standard method described in ISO 11844-2 standard. The lead was tested for its specific sensitivity to the presence of carboxylic acids. Dimensions of the copper specimens were $10 \times 50 \mathrm{~mm}$; dimensions of silver and lead specimens were $10 \times 25 \mathrm{~mm}$.

Silver and copper samples were prepared according to the ISO 11844-2 standard - the surface of the specimens was abraded with sandpaper of $1200 \mathrm{P}$ roughness, rinsed with deionized water, degreased with ethanol and air-dried. Lead specimens were prepared by abrading of the surface with sandpaper of $800 \mathrm{P}$ roughness and subsequent chemical cleaning in $20 \% \mathrm{HCl}$ followed by the second abrading of the surface with the abrasive wadding (3M Scotch-Brite CF-MF), rinsing with deionized water, degreasing with acetone and air-drying.

\subsection{Evaluation}

The mass gain gravimetric method and galvanostatic (GS) reduction were used to evaluate the exposed metal specimens. For the galvanostatic reduction, deaerated potassium chloride solution with concentration of $0.1 \mathrm{~mol}^{-1}$ was used and cathodic current density of $0.125 \mathrm{~mA} \cdot \mathrm{cm}^{-2}$ was applied.

The mass loss method was tested as well. However, it has shown to be a challenging method for the evaluation of lead specimens - any loss of the material due to the manipulation during specimens handling or during removal of the corrosion products may often mask the correct value of the mass losses. For that reason, only complete results from mass gain and galvanostatic reduction were considered for the evaluation. 


\subsection{Controlled conditions}

To evaluate the sensitivity of lead to specific levels of acetic acid in the atmosphere, $10 \times 50 \mathrm{~mm}$ lead specimens were exposed in the controlled environment. To reach desired environmental conditions, the lead specimens were placed in a chamber with an intake of dry air, wet air and air with the acetic acid. The acetic acid vapours were dosed by heating of a permeation tube filled with a small amount of the acid. The flow in all three intakes was controlled by valves to achieve the chosen conditions (see Table 3). The lead specimens were prepared in the same manner as for the former test. Five samples were exposed in each test for a period of 1 month.

\section{RESULTS AND DISCUSSION}

\subsection{Characterization of the exposure sites}

Table 1 summarizes the results of the characterization of the exposure sites in terms of temperature, relative humidity and level of the acetic and formic acid in the atmosphere.

Table 1 Characterization of the exposure sites

\begin{tabular}{|c|c|c|c|c|c|c|}
\hline \multirow{2}{*}{ Exposure site } & \multicolumn{2}{|c|}{ Climatic parameters } & \multicolumn{2}{c|}{ Conc. of acetic acid (ppm) } & \multicolumn{2}{c|}{ Conc. of formic acid (ppm) } \\
\cline { 2 - 7 } & $\begin{array}{c}\text { Temperature } \\
\left({ }^{\circ} \mathrm{C}\right)\end{array}$ & $\mathbf{R H}(\%)$ & $\begin{array}{c}\text { Passive } \\
\text { sampler }\end{array}$ & $\begin{array}{c}\text { Detection } \\
\text { tube }\end{array}$ & $\begin{array}{c}\text { Passive } \\
\text { sampler }\end{array}$ & $\begin{array}{c}\text { Detection } \\
\text { tube }\end{array}$ \\
\hline $\begin{array}{c}\text { Historic } \\
\left.\text { library (UCT }{ }^{1}\right)\end{array}$ & $18-29$ & $30-50$ & 0.3 & 0.3 & $<0.01$ & $<0.03$ \\
\hline $\begin{array}{c}\text { Mineralogical } \\
\text { collection (UCT }\end{array}$ & $15-26$ & $30-55$ & 0.1 & $<0.05$ & 0.1 & $<0.01$ \\
\hline $\begin{array}{c}\text { National Archive }- \\
\text { Hradčanská }\end{array}$ & 15 & 55 & 0.2 & $<0.05$ & $<0.005$ & $<0.03$ \\
\hline $\begin{array}{c}\text { National Library } \\
\text { Klementinum }\end{array}$ & $12-26$ & $45-60$ & 0.6 & 0.5 & $<0.01$ & 0.2 \\
\hline $\begin{array}{c}\text { Roztoky - } \\
\text { depository VU }\end{array}$ & $17-21$ & $35-52$ & 0.1 & $<0.05$ & $<0.004$ & 0.1 \\
\hline $\begin{array}{c}\text { Roztoky - } \\
\text { depository H }\end{array}$ & $16-23$ & $37-58$ & 0.3 & 0.4 & $<0.004$ & 0.1 \\
\hline
\end{tabular}

1 University of Chemistry and Technology

2 VU - Depository of Fine Arts, H - Musical Depository

Temperatures were in all cases below $30^{\circ} \mathrm{C}$ during the monitored period. The highest relative humidity was $60 \%$ in the case of Klementinum. These conditions itself, temperatures from $12{ }^{\circ} \mathrm{C}$ to $29{ }^{\circ} \mathrm{C}$ and levels of relative humidity up to $60 \%$, do not pose an excessive risk in terms of lead corrosion. The concentrations of acetic and formic acid vapours in the indoor atmosphere were evaluated using two methods, passive samplers and detection tubes. Overall, the values obtained with the passive samplers for acetic acid were in most cases higher compared to the detection tubes. The concentration of acetic acid was highest in the Klementinum site reaching values of $0.5-0.6 \mathrm{ppm}$. This concentration is high enough to increase significantly degradation of lead artifacts. The concentration of formic acid was in all cases lower than in the case of the acetic acid, not exceeding $0.1 \mathrm{ppm}$. Moreover, it has been shown that the presence of the formic acid tends to reduce the intensity of corrosion attack caused by acetic acid due to the formation of the thin protective film of formate corrosion products [10]. 


\subsection{Exposure results}

Table 2 shows the results for the specimens exposed for 3 months in the chosen exposure sites. The specimens were evaluated using mass gain and GS reduction. Evaluation of the silver and copper specimens allowed to classified the corrosivity of the exposure sites atmosphere according to the ISO 11844-1 standard.

Table 2 Evaluation of the exposed specimens

\begin{tabular}{|c|c|c|c|c|c|c|}
\hline \multirow{2}{*}{ Exposure site } & \multicolumn{3}{|c|}{ Mass gain $\left(\mathrm{mg} / \mathrm{m}^{2} \cdot \mathbf{a}\right)$} & \multicolumn{3}{c|}{ GS reduction $\left(\mathrm{mg} / \mathrm{m}^{2} \cdot \mathrm{a}\right)$} \\
\cline { 2 - 7 } & $\mathbf{A g}$ & $\mathbf{C u}$ & $\mathbf{P b}$ & $\mathbf{A g}$ & $\mathbf{C u}$ & $\mathbf{P b}$ \\
\hline Historic library (UCT) & 4 & 4 & $\mathbf{1 8 9}$ & 204 & 160 & $\mathbf{3 9 1 1}$ \\
\hline Mineralogical collection (UCT) & 1029 & 12 & $\mathbf{6 8 8}$ & 260 & 231 & $\mathbf{3 1 3 5}$ \\
\hline National Archive - Hradčanská & 176 & 0 & $\mathbf{7 0 7}$ & 100 & 232 & $\mathbf{3 3 0 0}$ \\
\hline National Library - Klementinum & 361 & 5 & $\mathbf{1 6 4 2}$ & 91 & 193 & $\mathbf{1 2 1 0}$ \\
\hline Roztoky - depository VU & 233 & 0 & $\mathbf{1 2 4 2}$ & 89 & 193 & $\mathbf{3 2 0 3}$ \\
\hline Roztoky - depository H & 166 & 48 & $\mathbf{4 4 6}$ & 172 & 222 & $\mathbf{3 0 4 3}$ \\
\hline
\end{tabular}

IC1 IC2

IC3

IC4

IC5

For the majority of the exposure sites, different corrosivity classification was reached based on the type of specimen (silver vs copper) or evaluation method. The most evident difference was noted in the Mineralogical Collection of the UCT Prague with IC5 classification for Ag specimens and IC1 classification for Cu specimens using the mass gain method and IC2 classification for Ag specimens and IC3 classification for Cu specimens using the GS reduction.

In all cases, lead specimens proved to be more sensitive to the indoor atmospheric conditions compared with other specimens. However, correlation with the detected concentration of carboxylic acids is not unambiguous and acetic acid concentration is not the only parameter causing the change in the lead corrosion rates. The mass gain method shows the highest corrosion rate for the lead specimens from the Klementinum exposure site, which is consistent with the results of the measured levels of the acetic acid concentration (Table 1). However, GS reduction shows a reverse trend with the lead specimens from the Klementinum exposure site having the lowest corrosion rate. Therefore, not only climatic conditions and concentration carboxylic acids but also the evaluation method can significantly alter the results.

\subsection{Measurements in controlled conditions}

The results of the exposures in controlled conditions (Table 3 ) show that at a tested average relative humidity of $50 \%$, no mass gain was detected on the specimens with 0 and $50 \mathrm{ppb}$ concentration of acetic acid vapours. Acetic acid concentration of $50 \mathrm{ppb}$ thus probably does not cause at $50 \% \mathrm{RH}$ any significant increase in the corrosivity of the atmosphere. The concentration of 500 and $1000 \mathrm{ppb}$ led to a major increase in the corrosivity, as shown by the results. Additional steps between 50 and $500 \mathrm{ppb}$ would be necessary to determine reliably the limit values of acetic acid concentration, above which the corrosivity of the atmosphere increases.

The levels of corrosion rates achieved in the controlled conditions are significantly higher compared to the results from the exposure sites. The major difference is steady a continuous intake of the organic pollutant in controlled laboratory conditions - the whole volume of the atmosphere in the chamber changed every 15-20 minutes thanks to the airflow. Additionally, longer exposure would probably lead to a decrease in the corrosion rates due to the protective properties of lead corrosion products. 
Table 3 Corrosion rate of the lead specimens exposed in specific conditions with known level of acetic acid in the atmosphere

\begin{tabular}{|c|c|c|c|}
\hline \multicolumn{2}{|c|}{ Test } & \multirow{2}{*}{ Mass gain $\left(\mathrm{g} / \mathrm{m}^{2} \cdot \mathrm{a}\right)$} \\
\cline { 1 - 2 } No. & RH $(\%)$ & Conc. of acetic acid $(\mathrm{ppb})$ & 0 \\
\hline 1 & 50 & 0 & 0 \\
\hline 2 & 50 & 50 & 16 \\
\hline 3 & 50 & 500 & 22 \\
\hline 4 & 50 & 1000 & 0 \\
\hline
\end{tabular}

\section{CONCLUSION}

Lead is significantly more sensitive to the presence of carboxylic acids in the atmosphere compared to the standard set of metal specimens used in the evaluation of the atmospheric corrosivity. Exposures in museum environments shown that lead specimens react to the presence of acetic acid even at low concentrations of hundreds of ppb. However, to obtain reliable information about the atmosphere and its corrosivity, proper methodology for evaluation of the mass changes is needed. With ongoing laboratory tests, it should be possible to find the exact levels of acetic acid concentration in relation to the relative humidity in the atmosphere that lead to significant changes in the lead corrosion resistance.

\section{ACKNOWLEDGEMENTS}

\section{The authors gratefully acknowledge the financial support by the Czech Ministry of Culture under NAKI II programme (No. DG18P02OVV050).}

\section{REFERENCES}

[1] SELWYN, L. et al. Lead (Pb). In: SELWYN, Lyndsie. et al. Metals and Corrosion: A Handbook for the Conservation Professional. 1st ed. Canada: Canadian Conservation Institute. 2004, pp. 115-123.

[2] COSTA, V., URBAN, F. Lead and its alloys: metallurgy, deterioration and conservation. Reviews in Conservation. 2005, vol. 6, pp. 48-62.

[3] SCHOTTE, B. Study of electrolytic reduction of corroded lead objects and application, characterization and testing of a protective lead carboxylate coating. Thesis submitted in fulfilment of the requirements for the degree of Doctor in Science. Universiteit Gent: Faculty of Science, 2007.

[4] NOVÁK, P. Conservation and renovation of lead and its alloys. In: Conservation and renovation of metals. 1 st ed. Brno: Technical museum v Brno. 2011. pp. 526-544. (in Czech).

[5] COSTA, V. Electrochemistry as a conservation tool: an overview. In Conservation Science 2002. London: Archetype Publications, 2003, pp. 88-95.

[6] TURGOOSE, S. The corrosion of lead and tin: before and after excavation. In Lead and Tin Studies in Conservation and Technology, United Kingdom Institute for Conservation: London. 1985, pp. 15-23.

[7] GIBSON, L.T., WATT, C.M. Acetic and formic acids emitted from wood samples and their effect on selected materials in museum environments. Corrosion Science. 2010, vol. 52, 172-178.

[8] COLES, E.L., GIBSON J.G., HINDE, R.M. The corrosion of lead by dilute aqueous organic acids. J. Appl. Chem. 1958, 341-348.

[9] TÉTREAULT, J., SIROIS, J., STAMATOPOULOU, E. Studies of lead corrosion in acetic acid environments. Studies in Conservation. 1998, vol. 43, pp. 17-32.

[10] TÉTREAULT, J., CANO, E., VAN BOMMEL, M., SCOTT, D., DENNIS, M., BARTHÉS-LABROUSSE, M. G., MINEL, L., ROBBIOLS, L. Corrosion of copper and lead by formaldehyde, formic and acetic acid vapours. Studies in Conservation. 2003, vol. 48, no. 4, pp. 237-250. 
[11] NIKLASSON, A., JOHANSSON, L. G., SVENSSON, J. E. Atmospheric corrosion of historical organ pipes: influence of acetic and formic acid vapour and water leaching on lead. In Metal 2004. Canberra: National Museum of Australia. 2004, pp. 273-280.

[12] STRACHOTOVÁ, K.Ch., KOUŘIL, M. Effect of the presence of corrosion products on the corrosion rate of lead during the exposition with paper packaging materials. Corrosion and Material Protection. 2018, vol. 62, no. 3, pp. 87-96.

[13] ISO 11844-2:2005. Corrosion of metals and alloys - Classification of low corrosivity of indoor atmospheres. Part 2: Determination of corrosion attack in indoor atmospheres. $14 \mathrm{p}$. 